\title{
EXCIMER LASER SURFACE TREATMENT OF 42CD4 AND Z160CDV12 STEEL SUBSTRATES
}

\author{
C. PAPAPHILIPPOU, D. PANTELIS and E. HONTZOPOULOS* \\ Laboratory MSS/MAT URA CNRS $n^{\circ}$ 850, Ecole Centrale de Paris, Grande Voie des Vignes, \\ F-92295 Châtenay-Malabry cedex, France \\ ${ }^{*}$ FORTH-Institute of Electronic Structure \& Lasers, P.O. Box 1527, GR-71110 Heraklion, \\ Crete, Greece
}

\begin{abstract}
The aim of this study is a better understanding of the interaction between Excimer irradiation and metallic materials, as well as the determination of the energy density thresholds of the different surface treatments. The experimental results, using a $\mathrm{KrF}(\lambda=0.248 \mu \mathrm{m})$ laser irradiation on $42 C D 4$ and Z160CDV12 steel substrates, are presented. An attempt was made to determine the relationship between the laser parameters, the dimensions of the formed craters (depth, length), the proportion of the ablated material and the surface roughness.
\end{abstract}

\section{1.- INTRODUCTION.}

The short wavelength of Excimer laser irradiation and the delivery of high energy density in a short time lead to surface modifications of different metallic materials [1], i.e. remelting [2] and ablation with crater formation without deterioration of the bulk properties. After the laser surface melting at a depth of few $\mu \mathrm{m}$, a very rapid solidification occurs. Consequently nanocrystalline or amorphous layers may appear.

The aim of this work is the modification of surface properties and morphology in order to improve its wear and corrosion resistance [3], for mechanical industrial applications. Additionally, it would be interesting to control the surface material removal in order to obtain a final product which satisfies the requirements in dimensional accuracy. Moreover, this treatment could be applied in aircraft and tool making industries, using materials which machining is very difficult.

\section{2.- EXPERIMENTAL.}

Polished samples of a constructional steel (AFNOR 42CD4-AISI 4142) and a high speed steel (AFNOR Z160CDV12-AISI D4) were used for this investigation. The chemical compositions of these two steels are shown in tables 1 and 2 .

Table 1. Chemical composition of the constructional steel:

\begin{tabular}{|c|c|c|c|c|c|c|}
\hline Element & $\mathrm{C}$ & $\mathrm{Mn}$ & $\mathrm{Si}$ & $\mathrm{Ni}$ & $\mathrm{Cr}$ & $\mathrm{Mo}$ \\
\hline mass \% & 0.42 & 0.75 & 0.35 & 0.15 & 1.0 & 0.2 \\
\hline
\end{tabular}

Table 2. Chemical composition of the high speed steel:

\begin{tabular}{|c|c|c|c|c|c|c|c|c|}
\hline Element & $\mathrm{C}$ & $\mathrm{Cr}$ & $\mathrm{Mo}$ & $\mathrm{V}$ & $\mathrm{Mn}$ & $\mathrm{Si}$ & $\mathrm{S}$ & $\mathrm{P}$ \\
\hline mass \% & 1.6 & 12.0 & 0.9 & 0.85 & 0.3 & 0.25 & $<0.03$ & $<0.03$ \\
\hline
\end{tabular}

The microstructure of the 42CD4 steel substrate is constituted of a tempered martensite, with an average microhardness of $300 \mathrm{HV}_{30 \mathrm{~g}}$. The $\mathrm{Z160CDV} 12$ steel has a micrographic structure with martensite and an average microhardness of $880 \mathrm{HV}_{30 \mathrm{~g}}$.

There are two main reasons for polishing the samples before irradiation. Firstly, by polishing, the surface conditions are similar for all experiments. On the other hand, the surfaces around the irradiated area have to be as smooth as possible, in order to determine the laser treated zones dimensions (depth and length) and the roughness. 
The samples were treated by a Lambda Physik excimer laser (LPX 210F), operating at a wavelength of $248 \mathrm{~nm}$ (KrF), with a relatively uniform beam profile. Experiments at widely different energy densities $\left(3.4-13.8 \mathrm{~J} / \mathrm{cm}^{2} / \mathrm{pulse}\right)$, frequencies $(10$ and $100 \mathrm{~Hz})$ and number of pulses $(500$ and 1000$)$ have been realized. The microstructural modifications of the laser treated zones are studied by optical microscopy and scanning electron microscopy. The surface roughness was measured by a surface profilometer (Hommel Tester T2). The proportion of the ablated material has been calculated by the use of a microbalance. Microhardness was measured on optical microscope with a $30 \mathrm{~g}$ load.

\section{3.- RESULTS AND DISCUSSION.}

3.1. Dimensions of the craters.

In the case of the $42 C D 4$ steel substrate, figure 1a shows that the length presents a minimum while the depth presents a maximum, for the same value of energy density $\left(10.2 \mathrm{~J} / \mathrm{cm}^{2} /\right.$ pulse).

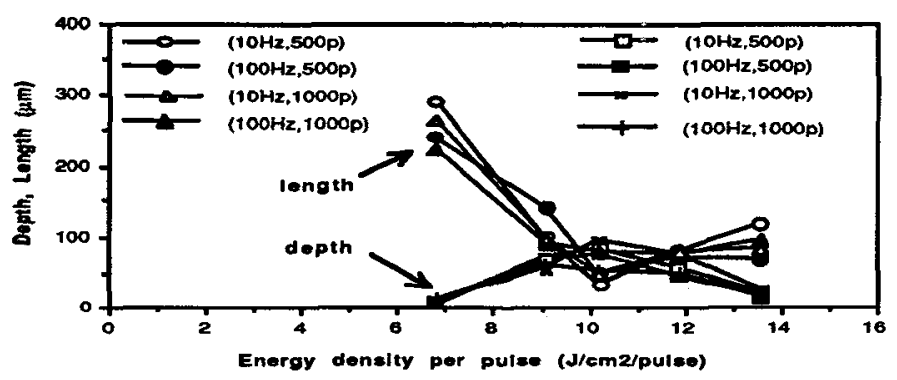

a) $42 \mathrm{CD} 4$

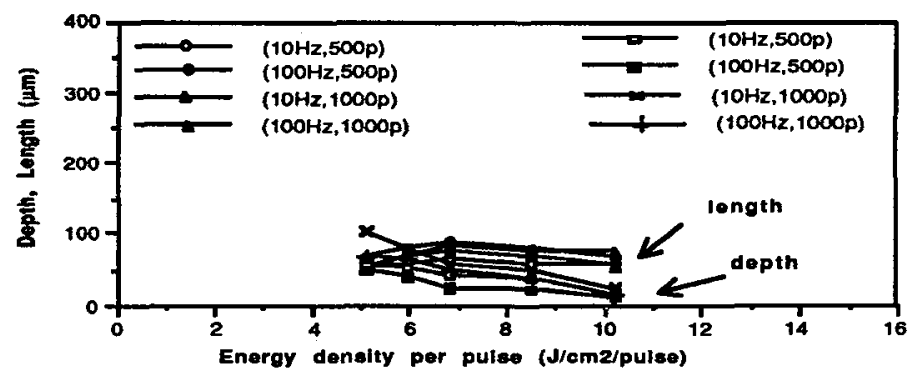

b) Z160CDV12

Fig. 1.- Correlation between the depth and the length of the formed crater and the energy density per pulse for different frequencies (10 and $100 \mathrm{~Hz}$ ) and number of pulses $(500$ and 1000).

In the case of the Z160CDV12 steel substrate (figure 1b), the length present a maximum while the depth presents a slight decrease with increasing energy density. Moreover, the beginning of the craters formation is observed for a value of $5.1 \mathrm{~J} / \mathrm{cm}^{2} /$ pulse. This value is inferior to that of the $42 \mathrm{CD} 4$ steel $\left(6,8 \mathrm{~J} / \mathrm{cm}^{2} / \mathrm{pulse}\right)$.

\subsection{Proportion of the ablated material.}

In Figure 2 the proportion of the ablated material (in percentage) is given as a function of laser energy density per pulse, for the $42 \mathrm{CD} 4$ steel. The $100 \%$ values correspond to the formation of clean craters, i.e. without molten material.In general, the tendency of increasing ablated material with increasing energy density per pulse is observed. It could also be added that:

-The proportion of ablated material increases with increasing frequency for the same values of energy density and number of pulses.

In higher frequencies the energy per pulse is given in shorter intervals compared to that of lower frequencies. As a result, for lower frequencies the substrate has a better resistance to the incident energy. On the contrary, for higher frequencies the flow of pulses is almost continuous and the ablation is more pronounced. 


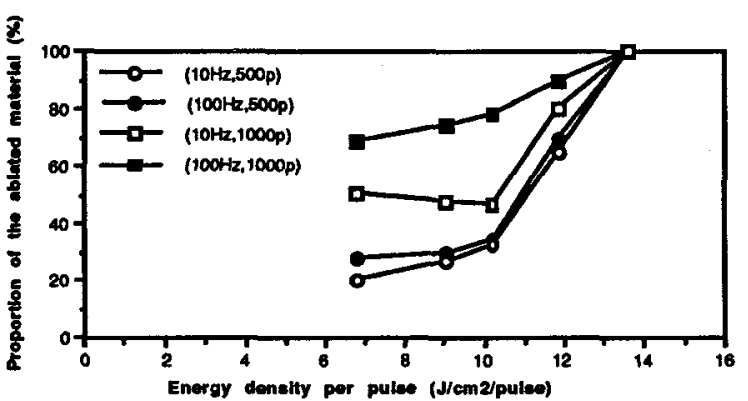

Fig. 2.- Proportion of the ablated material (\%) as a function of laser energy density per pulse, for the $42 C D 4$ steel.

- The proportion of the ablated material increases with increasing number of pulses for the same values of energy density and frequency.

This fact is explained by the increase of the total energy density absorbed by the substrate.

The study of the treatment of the Z160CDV12 steel confirms the above results.

\subsection{Roughness.}

The correlation between the roughness and the energy density per pulse is given in figure $3 a, b$ for both steels.

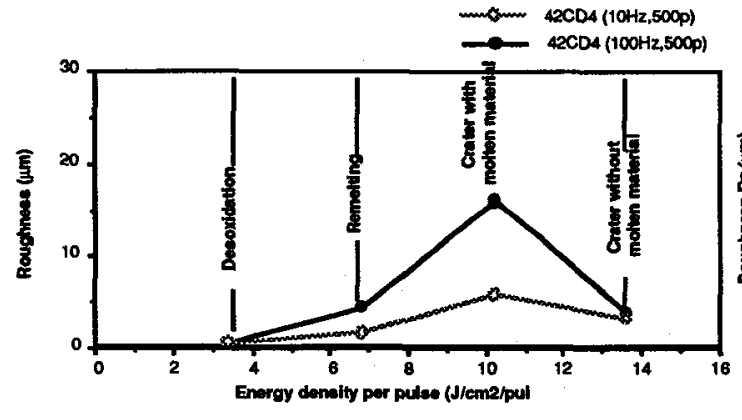

a) $42 \mathrm{CD} 4$ steel

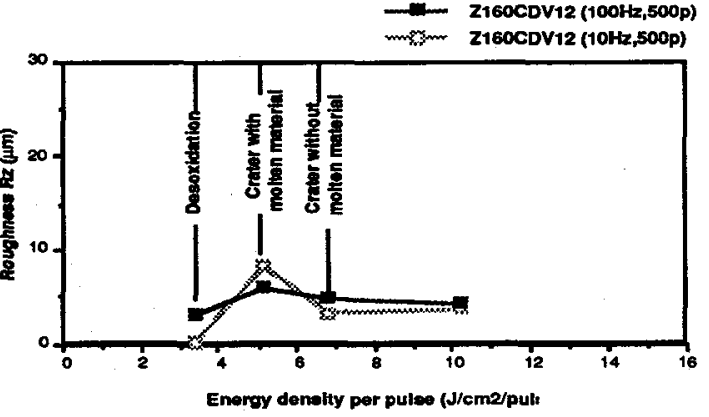

b) Z160CDV12

Fig. 3.- Correlation between roughness and energy density per pulse, for both steels.

In the case of $42 \mathrm{CD} 4$ steel, excimer laser irradiation with $3,4 \mathrm{~J} / \mathrm{cm}^{2} /$ pulse results to a slight increase in surface roughness. As the micrographic observation does not reveal remelting or ablation of the surface, it is suggested that the mentioned increase of the roughness is due to the surface desoxidation.

At $6,8 \mathrm{~J} / \mathrm{cm}^{2} /$ pulse, homogeneous evaporation or remelting (fig. 4) of a superficial layer of few microns occurs. The roughness rises only in a small range.

The irradiation of the substrate with $10,2 \mathrm{~J} / \mathrm{cm}^{2} /$ pulse results in a deep roughening which is due to the formation of a crater containing molten material (fig. 5). The microhardness of the molten areas reaches $600 \mathrm{HV}$. In all the above cases the microhardness near the surface does not change. This fact confirms the absence of a HAZ. The asymmetric shape of this molten material is due to hydrodynamical motion of molten material under convection and surface tension.

As the energy increases up to $12,8 \mathrm{~J} / \mathrm{cm}^{2} /$ pulse a decrease in roughness is observed. This could be explained by plasma formation which absorbs a part of the incident energy (screen effect). In this case the depth of the crater decreases (figure 6).

The same phenomena occur for the high speed steel (figure $3 \mathrm{~b}$ and figure 7). Meanwhile in this case the observed phenomena appear for values of energy density inferior to that of the constructional steel. 


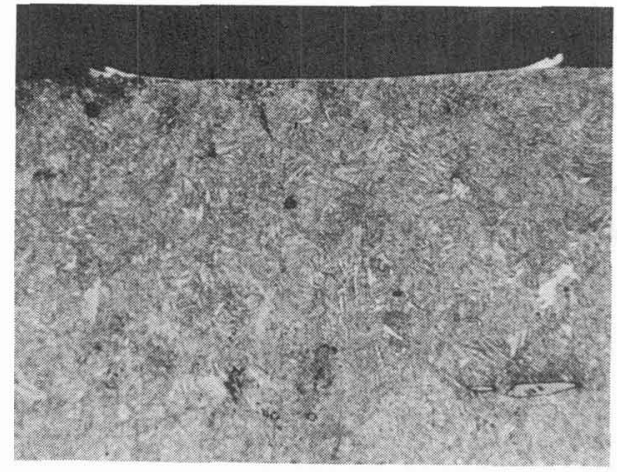

(a)

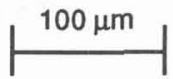

(b)
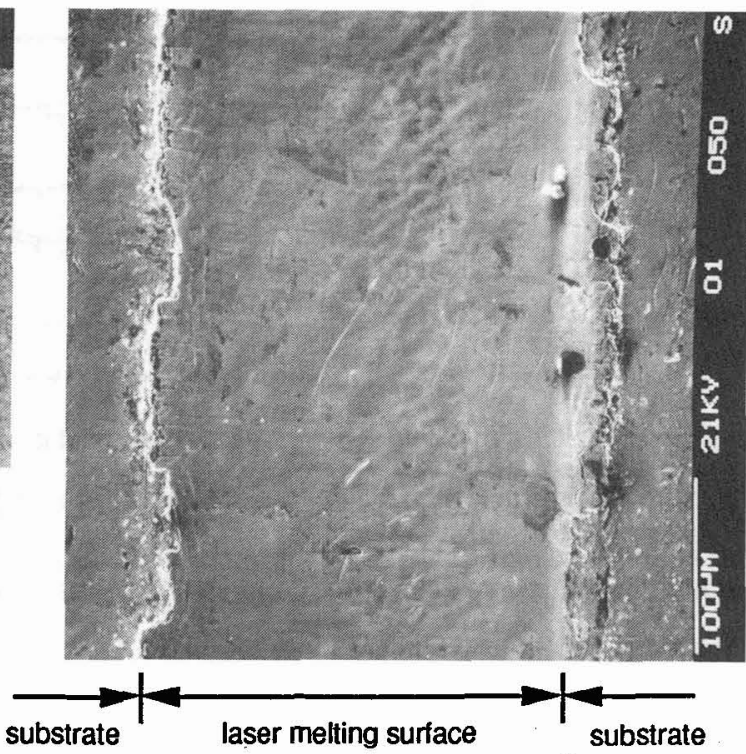

Fig. 4. - Surface remelting after excimer laser irradiation on $42 \mathrm{CD} 4$ steel substrate $\left(6.8 . J / \mathrm{cm}^{2} / \mathrm{pulse}, 500 \mathrm{pulses}\right.$, $100 \mathrm{~Hz}$.

(a): Optical macrograph and (b): Electronic macrograph on the treated surface.

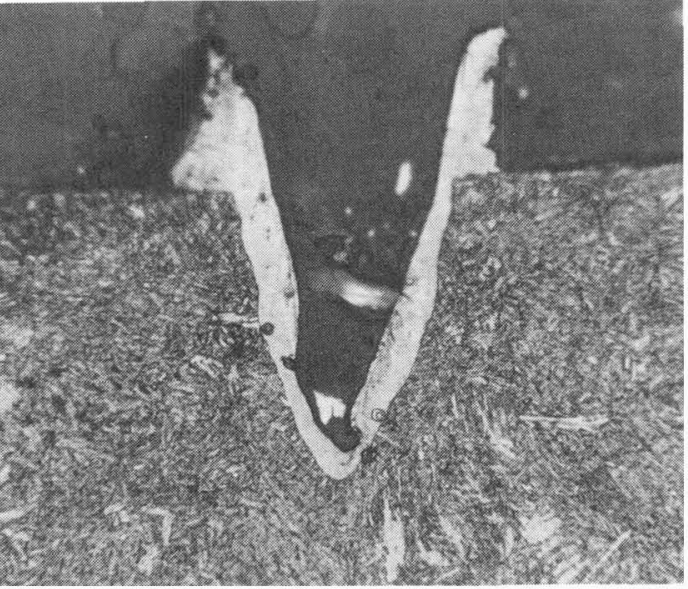

$100 \mu \mathrm{m}$

Fig. 5. - Optical macrograph of the formed crater after excimer laser irradiation on $42 \mathrm{CD} 4$ steel substrate( 10.2 $\mathrm{J} / \mathrm{cm}^{2} /$ pulse, 500 pulses, $100 \mathrm{~Hz}$ ). 


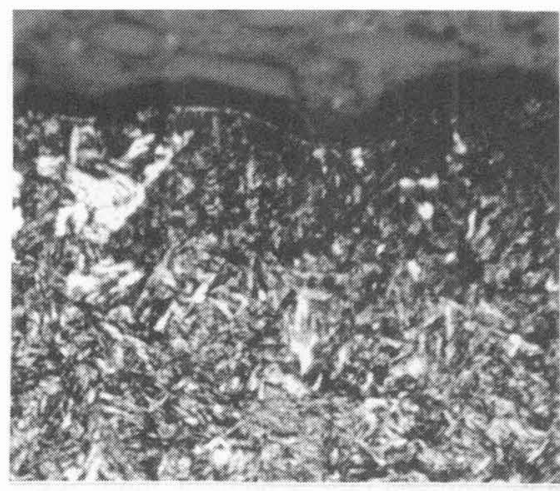

(a)
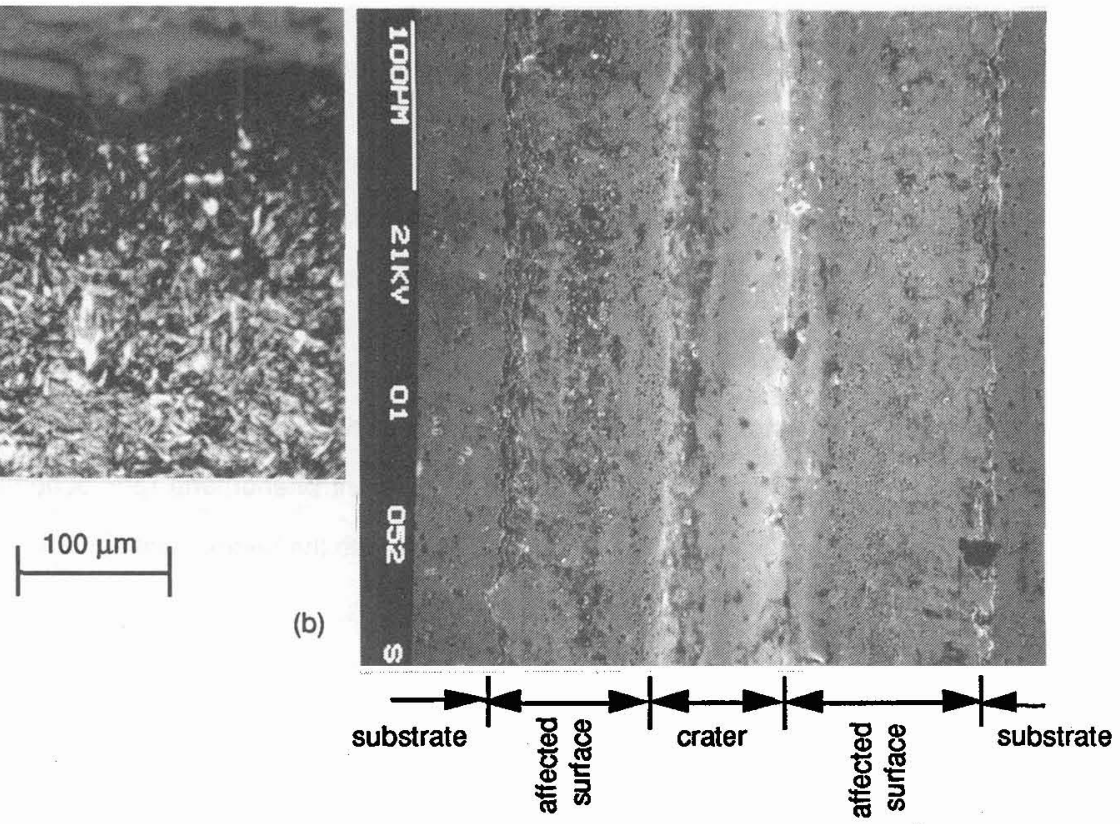

Fig. 6. - Formed crater after excimer laser irradiation on 42 CD4 steel substrate $\left(13.6 \mathrm{~J} / \mathrm{cm}^{2} /\right.$ pulse, 500 pulses, 100 Hz)

(a): Optical macrograph and (b): Electronic macrograph on the treated surface.

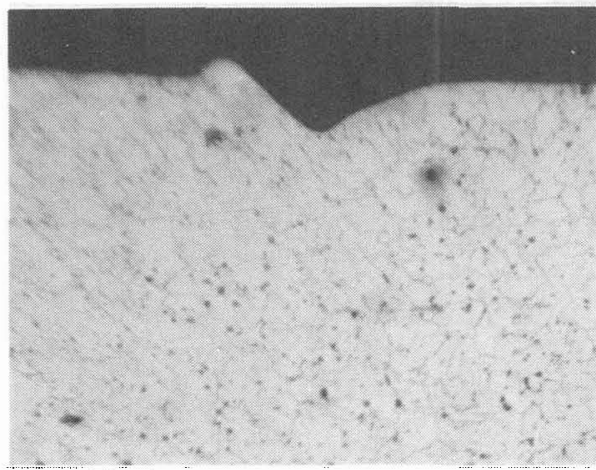

(a)

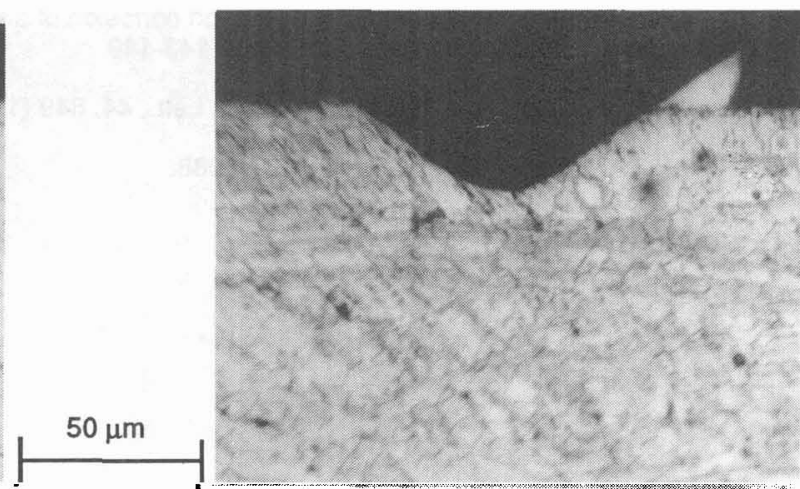

(b)

Fig. 7. - Macrographs of formed craters after excimer laser irradiation on Z160CDV12 steel substrates.

(a): $10.2 \mathrm{~J} / \mathrm{cm}^{2}$ /pulse, 500 pulses, $10 \mathrm{~Hz}$.

(b): $.6 .8 \mathrm{~J} / \mathrm{cm}^{2} /$ pulse, 500 pulses, $100 \mathrm{~Hz}$

This behavior could be explained by the following facts:

- firstly, the higher percentage of carbon as well as its homogeneous distribution in the martensitic structure of the high speed steel lowers the melting point and accelerates the vaporization phenomenon.

- secondly, the chrome percentage, which is a relatively volatile element, is higher in the high speed steel.

In addition the stage of remelting is not observed. 


\section{4.- Ablation models.}

Various models are proposed in order to explain the ablation phenomena of different materials. The behavior of the constructional and the high speed steels shows several common points with two models:

a) The thermal model [4]

- the crater is not always clean;

- the molten material is ejected in a cone of $60-70^{\circ}$.

However, in this model a symmetrical crater is predicted, which is not the case here.

b) The dynamic model [5]

- there are different stages in the ablation, depending on the treated materials.

\section{4.- CONCLUSIONS.}

It is possible to produce different kinds of surface modification by excimer laser irradiation, depending on the laser parameters as well as on the irradiated material.

The study of the obtained curves confirms the sequence of different phenomena (photochemical, thermal and plasma formation).

The behavior of the treated materials show several common points with the thermal and dynamic models.

\section{REFERENCES.}

\section{[1] J. ARNOLD, F. DAYSINGER}

"Surface structures produced by excimer lasers during ablation of metals"

Proceedings of the Third European Conference on Laser Treatment of Materials, Erlangen, RFA, September 1719,1990, p.859-870

[2] H. W. BERGMANN, E. SCHUBERT

"Modification of metal surfaces by excimer laser treatment - state of the art"

Surface Engineering with High Energy Beams

Proceedings of the Second International Seminar, Lisbon, Portugal, September 25-27, 1989, p. 29-51

[3] D. R. BAER, I. G. WRIGHT, T. R. JERVIS

"The effects of excimer laser annealing and yttria on corrosion of an $\mathrm{FeCrNi}$ at $700^{\circ} \mathrm{C}$.

Surface and Interface Analysis, Vol. 15, 1990, p. 143-149

[4] B.J.GARRISON, R.SRINIVASAN. Appl. Phys. Lett., 44, 849 (1984).

[5] R.SRINIVASAN and al. Laser Che., 9, (147) 1988. 